ISSN 0258-7122

Bangladesh J. Agril. Res. 34(3) : 505-515, September 2009

\title{
GENOTYPIC VARIATION IN TRADITIONAL RICE VARIETIES FOR CHLOROPHYLL CONTENT, SPAD VALUE AND NITROGEN USE EFFICIENCY
}

\author{
MiAn SAYEED HASSAN ${ }^{1}$, ABUL KHAIR ${ }^{2}$, M. MOYNUL HAQUE ${ }^{3}$ \\ ABUL KALAM AZAD ${ }^{4}$ AND ABDUL HAMID ${ }^{5}$
}

\begin{abstract}
Nitrogen \% in both straw and grain, nitrogen uptake by straw and grain, total nitrogen uptake and physiological nitrogen use efficiency (PNUE) showed significant differences due to variable nutrient levels at maturity in traditional rice varieties. PNUE ranges from 40.58 to $49.88(\mathrm{~kg} / \mathrm{kg} \mathrm{N})$. Significantly higher PNUE without addition of nitrogen (Zero N) indicated the ability of utilization of the native nitrogen by traditional varieties. Traditional varieties produced $49.88 \mathrm{~kg}$ grain by the utilization of zero nitrogen treatment followed by $45.93 \mathrm{~kg}$ grain in cowdung (10 t/ha), while $40.58 \mathrm{~kg}$ grain by the application of $80 \mathrm{~kg} / \mathrm{ha}$ nitrogen. The higher PNUE in zero nitrogen treatment confirmed the ability of producing similar yield level compared to added nitrogen treatment. Bashful chikon, might be important due to higher nitrogen content and Badiruzzman considered due to more straw nitrogen $(0.71 \%)$. Barud also showed excellence with regards to PNUE and total nitrogen uptake. Leaf chlorophyll profile showed a very consistent level in all the varieties except Laichi. Soil plant analysis development (SPAD) value ranged from 34.06 to 41.69, while leaf nitrogen ranged from 2.99 to $3.49 \%$. SPAD value recorded over time showed four distinct patterns during 15 to 90 DAT.
\end{abstract}

Key Words : Genotypic variation, rice varieties, SPAD value, nitrogen use efficiency.

\section{Introduction}

Nitrogen is the most essential element in determining the yield potential of intensified agricultural system. Additional doses of nitrogen are usually applied to increase grain yield (De Datta and Buresh, 1989). Nitrogen fertilizers are not used efficiently because rice is grown in an environment that is conducive to nitrogen losses through nitrification-denitrification, ammonia volatilization, runoff and leaching. The amount of nitrogen uptake and nitrogen use efficiency (NUE) of crop depends on the yield level and environmental conditions (Yoshida, 1983). Strategies has been developed to synchronize plant $\mathrm{N}$ demand and $\mathrm{N}$ supply from soil fertilizer through proper timing, rate, placement and use of modified forms of fertilizer (De Datta and Buresh, 1989; Cassman et al., 1993).

\footnotetext{
${ }^{1 \& 4}$ Crops Division, BARC, Farmgate, Dhaka $1215,{ }^{2}$ Department of Botany, Jahanjirnagar University, Savar, Dhaka, ${ }^{3 \& 5}$ Dept. of Agronomy, BSMRAU, Gazipur, Bangladesh .
} 
Rice genotypes were reported to differ significantly in relation to nitrogen uptake, grain yield, nitrogen translocation efficiency and NUE (Borah and Deka, 1994). Rice genotypes were distinguished (Gourley et al., 1993) as efficient, inefficient, and inferior types based on grain yield response in relation to nitrogen response. Pinto et al. (2001) identified N-use efficient rice genotypes under low level of available soil $\mathrm{N}$ and these efficient rice genotypes could be used in breeding programme to improve rice production in poor soils which would be useful for the resource poor farmers who have limited access to the use of $\mathrm{N}$ fertilizer. Plant breeding techniques may help to develop rice varieties that are resistant to pests, disease, and adverse environmental conditions, such as drought, nutrient deficiencies, toxicity and salinity (Singh et al., 1998).

Chlorophyll pigments play an important role in the photosynthetic process as well as biomass production. Genotypes maintaining higher leaf chlorophyll-a and chlorophyll-b during growth period may be considered potential donor for the ability of producing higher biomass and photosynthetic capacity. Higher photosynthesis rate is supported by leaf chlorophyll content in leaf blades (Miah et al., 1997). The chlorophyll meter or SPAD (Soil plant analysis development) offers a new strategy for synchronizing $\mathrm{N}$ application with actual crop demand in rice (Peng et al., 1996; Balasubramanian et al., 1999). The chlorophyll meter indicates the need of a nitrogen top dressing that would result greater agronomic efficiency of nitrogen fertilizer than commonly pre-application of nitrogen (Hussain et al., 2000). It was well established that SPAD based nitrogen management needs considerably lower amount of nitrogen than the standard nitrogen management practices without any yield losses (Ali, 2005; Miah and Ahmed, 2002). Considering the above facts, this study was undertaken to evaluate the traditional rice varieties in respect of chlorophyll content, SPAD value and nitrogen use efficiency.

\section{Materials and Method}

A field experiment was conducted at Bangabandhu Sheikh Mujibur Rahman Agricultural University (BSMRAU) experimental farm during Aman growing season of 2003. Three variable nutrient levels and eight traditional Aman rice varieties formed the treatment variables. The experiment was conducted in split plot design with three replications. The variable nutrient levels that formed the main plot treatment were i) zero nitrogen, ii) added nitrogen (nitrogen $80 \mathrm{~kg} / \mathrm{ha}$, and iii) cowdung (10 t/ha; oven dry basis). Eight diverse varieties formed the sub-plot treatments were, $\mathrm{V}_{1}$ - Badiruzzaman, $\mathrm{V}_{2}$ - Golapi, $\mathrm{V}_{3}$ - Laichi, $\mathrm{V}_{4}$ Banshful chikon, $\mathrm{V}_{5}-$ Malanchi, $\mathrm{V}_{6}$-Barud, $\mathrm{V}_{7}-$ Kamarga chikon and $\mathrm{V}_{8}$ Tulshimala. The major soil chemical properties of the experimental field were total nitrogen (N) $0.11 \%$, phosphorous (P) $2.72 \mu \mathrm{g} \mathrm{g}^{-1}$ soil, potassium (K) 0.197 meq $100 \mathrm{~g}^{-1}$ soil and sulfur (S) 7.90 micro g/g soils. Seeds were soaked on 24 
July 2003. The sprouted seeds were placed in a well-managed seedbed. Necessary cares were taken in the seed bed. A common nutrient dose of 20-40-10 $\mathrm{kg} / \mathrm{ha}$ of P-K-S were incorporated as basal dose except cowdung. Welldecomposed cowdung was incorporated in the assigned plots. Thirty-one days old seedlings were transplanted in $5 \times 3 \mathrm{~m}$ plot with a spacing of $25 \times 15 \mathrm{~cm}$ on 28 August 2002. Nitrogen in the form of urea was top-dressed at 15 DAT, 35, and 55 DAT. The experimental plots were kept clean by hand weeding until flowering. Other intercultural operations were done as and when necessary. SPAD (Soil plant analysis development) readings were recorded at every three days interval starting from 15 DAT to 90 DAT. Fully expanded leaves were measured and after flowering, the flag leaves were considered. Three measurements were recorded from each hill and three hills were considered in each plot. Besides this periodical recording during flowering, a separate SPAD records were taken (seven measurements from each plot) and subsequently the specific leaves were sampled (destructive) for the determination of leaf chlorophyll-a, chlorophyll-b, total chlorophyll and leaf nitrogen content. A chlorophyll meter (SPAD-502, Minolta Camera Co. Japan) was used for recording the SPAD value. The total chlorophyll was calculated from chlorophyll-a and chlorophyll-b. The leaf samples were oven dried at $70^{\circ} \mathrm{C}$ at around 72 hours with proper leveling for leaf nitrogen analysis. Straw and grain samples were taken separately at maturity for nitrogen analysis by Kjeldhal method. Total nitrogen uptake and physiological nitrogen use efficiency were calculated by the following formulae:

Total nitrogen uptake $(\mathrm{g} / \mathrm{hill})=$ Total nitrogen $\% \mathrm{x}$ above ground total dry matter

Physiological nitrogen use efficiency $=\frac{\text { Grain yield (at } 14 \% \text { moisture) }}{\text { Total nitrogen uptake }}$ $(\mathrm{Kg} / \mathrm{kg}-\mathrm{N})$

ANOVA was performed and means were separated by DMRT using MSTAT-C. Beside this, raw data were compiled and regression analyses and graphs were prepared using Microsoft Excel.

\section{Results and Discussion}

\section{Nitrogen uptake and physiological nitrogen efficiency (PNUE)}

Nitrogen \% in both straw and grain, nitrogen uptake by straw and grain, total nitrogen uptake and PNUE showed significant differences due to variable nutrient levels at maturity (Table 1). Borah and Deka (1994) reported a great variation in grain yield, $\mathrm{N}$ uptake, translocation efficiency and $\mathrm{N}$ use efficiency among rice varieties. Grain nitrogen \% ranged from 1.30 to $1.48 \%$ and straw nitrogen \% ranged from 0.50 to $0.73 \%$, while total nitrogen uptake varied within 
70.98 and 93.77 (kg/ha). Grain nitrogen \% was considerably higher than nitrogen $\%$ in straw. Application of nitrogen $(80 \mathrm{~kg} / \mathrm{ha})$ showed significantly higher nitrogen content as well as nitrogen uptake. Significantly higher PNUE without addition of nitrogen (Zero $\mathrm{N}$ ) indicated the ability of utilization of the native nitrogen by traditional varieties. PNUE ranges from 40.58 to 49.88 (kg grain $/ \mathrm{kg}$ $\mathrm{N})$. Results indicated that traditional cultivars produced $49.88 \mathrm{~kg}$ grain by the utilization of zero nitrogen treatment followed by $45.93 \mathrm{~kg}$ grain in cowdung (10 $\mathrm{t} / \mathrm{ha}$, while $40.58 \mathrm{~kg}$ grain by the application of $80 \mathrm{~kg} / \mathrm{ha}$ nitrogen. The higher PNUE in zero nitrogen treatment confirmed the ability of producing similar yield level compared to added nitrogen treatment. This corroborates with the findings of Singh et al. (1998) who reported nitrogen efficient genotypes that produced high yield at both low and high $\mathrm{N}$ supply.

Table 1. Effect of variable nutrient levels on nitrogen\%, nitrogen uptake and physiological nitrogen use efficiency (PNUE) of traditional rice varieties during T. Aman 2003.

\begin{tabular}{l|c|c|c|c|c|c}
\hline $\begin{array}{c}\text { Treatments (nutrient } \\
\text { levels) }\end{array}$ & \multicolumn{2}{|c|}{$\%$ Nitrogen } & \multicolumn{2}{c|}{$\begin{array}{c}\text { Nitrogen uptake } \\
\text { (kg/ha) }\end{array}$} & $\begin{array}{c}\text { Total N } \\
\text { uptake } \\
(\mathrm{kg} / \mathrm{ha})\end{array}$ & $\begin{array}{c}\text { PNUE } \\
(\mathrm{kg} / \mathrm{ha} \text { N) }\end{array}$ \\
\cline { 2 - 6 } & Grain & Straw & Grain & Straw & & \\
\hline Zero nitrogen & $1.30 \mathrm{~b}$ & $0.50 \mathrm{~b}$ & $45.29 \mathrm{c}$ & $25.70 \mathrm{~b}$ & $70.98 \mathrm{c}$ & $49.88 \mathrm{a}$ \\
Nitrogen (80 kg/ha) & $1.48 \mathrm{a}$ & $0.73 \mathrm{a}$ & $55.81 \mathrm{a}$ & $37.96 \mathrm{a}$ & $93.77 \mathrm{a}$ & $40.58 \mathrm{~b}$ \\
Cowdung (10 t/ha) & $1.34 \mathrm{~b}$ & $0.59 \mathrm{~b}$ & $49.97 \mathrm{~b}$ & $31.99 \mathrm{ab}$ & $81.95 \mathrm{~b}$ & $45.93 \mathrm{ab}$ \\
\hline
\end{tabular}

Means followed by same letter (s) do not differ significantly at $5 \%$ level by DMRT

Traditional rice varieties showed significant differences on nitrogen \%, nitrogen uptake (straw, grain, and total) and PNUE at variable nutrient levels (Table 2). Among the varieties, Bashful chikon, Tulshimala, Badiruzzma, and Kamarga chikon accounted significantly similar grain nitrogen content. Grain nitrogen \% ranged from 1.13 to $1.53 \%$ while straw nitrogen \% ranged from 0.78 to $0.71 \%$. The cultivar Bashful chikon collected from Jhalokati might be promising due to higher nitrogen content in grain as well as good grain shape and size although yielded low. While, Badiruzzman containing more straw nitrogen $(0.71 \%)$ might be considered valuable as fodder. The variety Barud ranked top for PNUE, which were statistically similar to all other cultivars except Badiruzzma and Bashful chikon. Barud also showed excellence with regards to total nitrogen uptake. The consistence in performance of Barud might be due to the longer growth duration, which resulted more TDM as well s grain yield and related attributes. 
Table 2. Performance of traditional rice varieties for nitrogen \%, nitrogen uptake and physiological nitrogen use efficiency (PNUE) during T. Aus 2003.

\begin{tabular}{|c|c|c|c|c|c|c|}
\hline \multirow[t]{2}{*}{ Varieties } & \multicolumn{2}{|c|}{ \% Nitrogen } & \multicolumn{2}{|c|}{$\begin{array}{l}\text { Nitrogen uptake } \\
\text { (kg/ha) }\end{array}$} & \multirow{2}{*}{$\begin{array}{l}\text { Total N } \\
\text { uptake } \\
\text { (kg/ha) }\end{array}$} & \multirow[t]{2}{*}{$\begin{array}{c}\text { PNUE } \\
(\mathrm{kg} / \mathrm{ha} \mathrm{N})\end{array}$} \\
\hline & Grain & Straw & Grain & Straw & & \\
\hline Badiruzzman & $1.45 a b c$ & $0.71 \mathrm{a}$ & 51.06ab & $33.57 b c$ & 84.63abc & 42.8lbc \\
\hline Golapi & $1.38 \mathrm{bcd}$ & $0.58 \mathrm{~b}$ & $47.88 \mathrm{ab}$ & $28.03 \mathrm{c}$ & 75.92 bc & $46.46 \mathrm{ab}$ \\
\hline Laichi & $1.33 \mathrm{~cd}$ & $0.64 \mathrm{~b}$ & $45.46 \mathrm{~b}$ & $27.43 \mathrm{c}$ & $72.88 \mathrm{c}$ & $47.13 \mathrm{ab}$ \\
\hline Basfulehikon & $1.53 \mathrm{a}$ & $0.61 \mathrm{~b}$ & $51.07 \mathrm{ab}$ & 36.0lab & $87.08 \mathrm{ab}$ & 38.51 c \\
\hline Malanchi & $1.26 \mathrm{~d}$ & $0.58 \mathrm{~b}$ & $46.34 b$ & 31.99bc & 78.32 be & 47.33ab \\
\hline Barud & $1.13 \mathrm{e}$ & $0.57 \mathrm{~b}$ & $49.76 \mathrm{ab}$ & $40.67 \mathrm{a}$ & 90.43 a & 49.37 a \\
\hline Kamerga chikon & $1.42 \mathrm{abc}$ & $0.57 \mathrm{~b}$ & 55.13 a & 29.22 bc & 84.35 abc & $46.84 \mathrm{ab}$ \\
\hline Tulshimala & $1.50 \mathrm{ab}$ & $0.59 \mathrm{~b}$ & 56.13 a & $28.14 \mathrm{e}$ & 84.27 abc & $45.27 \mathrm{ab}$ \\
\hline
\end{tabular}

Means followed by same letter (s) do not differ significantly at 5\% level by DMRT

\section{Leaf chlorophyll profile and SPAD Value}

Results revealed that no significant variations were observed in leaf chlorophyll profile, while SPAD value and nitrogen content (\%) showed significant differences under variable nutrient levels (Table 3). SPAD value may also be used directly to monitor leaf N status in rice (Peng et al., 1996) and determine the time of $\mathrm{N}$ top dressing. Results revealed that SPAD value ranged from 36.36 to 41.85. Application of higher nitrogen $(80 \mathrm{~kg} / \mathrm{ha})$ recorded significantly higher SPAD value compared to cowdung and zero $\mathrm{N}$ environments. Similar trend was also found in case of leaf $\mathrm{N} \%$ which ranged from 3.12 to $3.48 \%$. Takabe et al. (1990) pointed out the importance of the chlorophyll meter that provides a simple quick and non-destructive method for estimating area-based leaf $\mathrm{N}$ concentration. Similarly, the varieties showed a very consistent level of chlorophyll profile except the variety Laichi which accounted considerably less amount of chlorophyll-a, chlorophyll-b, and total chlorophyll (Table 4). This might be due to incidence of rice Tungro disease. Similar effect was also observed in respect of SPAD value and leaf nitrogen content for Laichi. SPAD value ranged from 34.06 to 41.69 , while leaf nitrogen ranged from 2.99 to $3.49 \%$. At flowering, Bashful chikon and Tulshimala accounted significantly higher SPAD value and leaf nitrogen \%. These results satisfy the earlier findings of higher grain nitrogen $\%$ in Bashful chikon and Tulshimala and also the higher value of leaf nitrogen $\%$ at flowering as reflected in straw N\% at maturity. Several workers reported higher productivity (Panaullah et al., 1999; Islam et al., 1998) and agronomic efficiency of chlorophyll meter-based application of $\mathrm{N}$ doses compared to conventional 
method of $\mathrm{N}$ application in rice. Leaf $\mathrm{N} \%$ showed significant differences due to variable nutrient environments.

Table 3. Effect of variable nutrient levels on leaf chlorophyll profile, SPAD value and nitrogen \% of traditional rice varieties during T. Aman 2003.

\begin{tabular}{l|c|c|c|c|c}
\hline \multirow{2}{*}{$\begin{array}{c}\text { Treatments (nutrient } \\
\text { levels) }\end{array}$} & \multicolumn{3}{c|}{ Chlorophyll } & \multicolumn{2}{c}{ Corresponding leaves } \\
\cline { 2 - 7 } & $\mathrm{A}$ & $\mathrm{B}$ & Total & SPAD values & Nitrogen \% \\
\hline Zero nitrogen & 0.820 & 0.245 & 1.064 & $36.36 \mathrm{~b}$ & $3.12 \mathrm{c}$ \\
Nitrogen (80 kg/ha) & 0.990 & 0.306 & 1.296 & $41.85 \mathrm{a}$ & $3.48 \mathrm{a}$ \\
Cowdung (10 t/ha) & 0.868 & 0.249 & 1.117 & $38.15 \mathrm{~b}$ & $3.26 \mathrm{~b}$ \\
\hline
\end{tabular}

Means followed by same letter (s) do not differ significantly at 5\% level by DMRT.

Functional relationships were found with leaf nitrogen \% and chlorophyll profiles (chlorophyll-a, chlorophyll-b with total chlorophyll); SPAD values with chlorophyll-a, chlorophyll-b with leaf nitrogen \% (Fig. 1). It was found that chlorophyll-a, chlorophyll-b and total chlorophyll content showed linear and positive relationship with leaf nitrogen $\%$; the $R^{2}$ values being $0.635,0.631$, and 0.684, respectively (Fig. l:A1-A3). This relationship indicated that chlorophyll profiles were highly dependent on the leaf $\mathrm{N}$ content. Similarly, total chlorophyll, chlorophyll, and leaf $\mathrm{N} \%$ also showed linear and positive relationship with SPAD values at flowering. The corresponding $\mathrm{R}^{2}$ values were 0.785 , 0.745, and 0.696, respectively (Fig. 1:B1-B3). Linear and positive relationship of SPAD values with total chlorophyll, chlorophyll-a and leaf nitrogen \% indicated the dependence of SPAD values with chlorophyll and nitrogen content of leaf at flowering.

Table 4. Performance of traditional rice varieties for leaf chlorophyll profile, SPAD value and nitrogen \% during T. Aus 2003.

\begin{tabular}{|c|c|c|c|c|c|}
\hline \multirow[t]{2}{*}{ Varieties } & \multicolumn{3}{|c|}{ Chlorophyll } & \multicolumn{2}{|c|}{ Corresponding leaves } \\
\hline & A & $\mathrm{B}$ & Total & SPAD values & Nitrogen (\%) \\
\hline Badiruzzman & 0.977 & 0.274 & 1.251 & $39.38 \mathrm{bc}$ & $3.48 \mathrm{a}$ \\
\hline Golapi & 0.910 & 0.267 & 1.177 & $38.08 \mathrm{~cd}$ & $3.20 \mathrm{c}$ \\
\hline Laichi & 0.680 & 0.218 & 0.898 & $34.06 \mathrm{e}$ & $2.99 \mathrm{~d}$ \\
\hline Basfulehikon & 0.932 & 0.288 & 1.219 & $42.03 a$ & $3.44 a$ \\
\hline Malanchi & 0.919 & 0.269 & 1.188 & $37.01 \mathrm{~d}$ & $3.21 \mathrm{c}$ \\
\hline Barud & 0.944 & 0.258 & 1.202 & $40.10 \mathrm{ab}$ & $3.16 \mathrm{c}$ \\
\hline Kamerga chikon & 0.828 & 0.269 & 1.096 & 37.94cd & $3.30 \mathrm{~b}$ \\
\hline Tulshimala & 0.953 & 0.288 & 1.240 & 41.69 a & 3.49 a \\
\hline
\end{tabular}

Means followed by same letter (s) do not differ significantly at $5 \%$ level by DMRT 

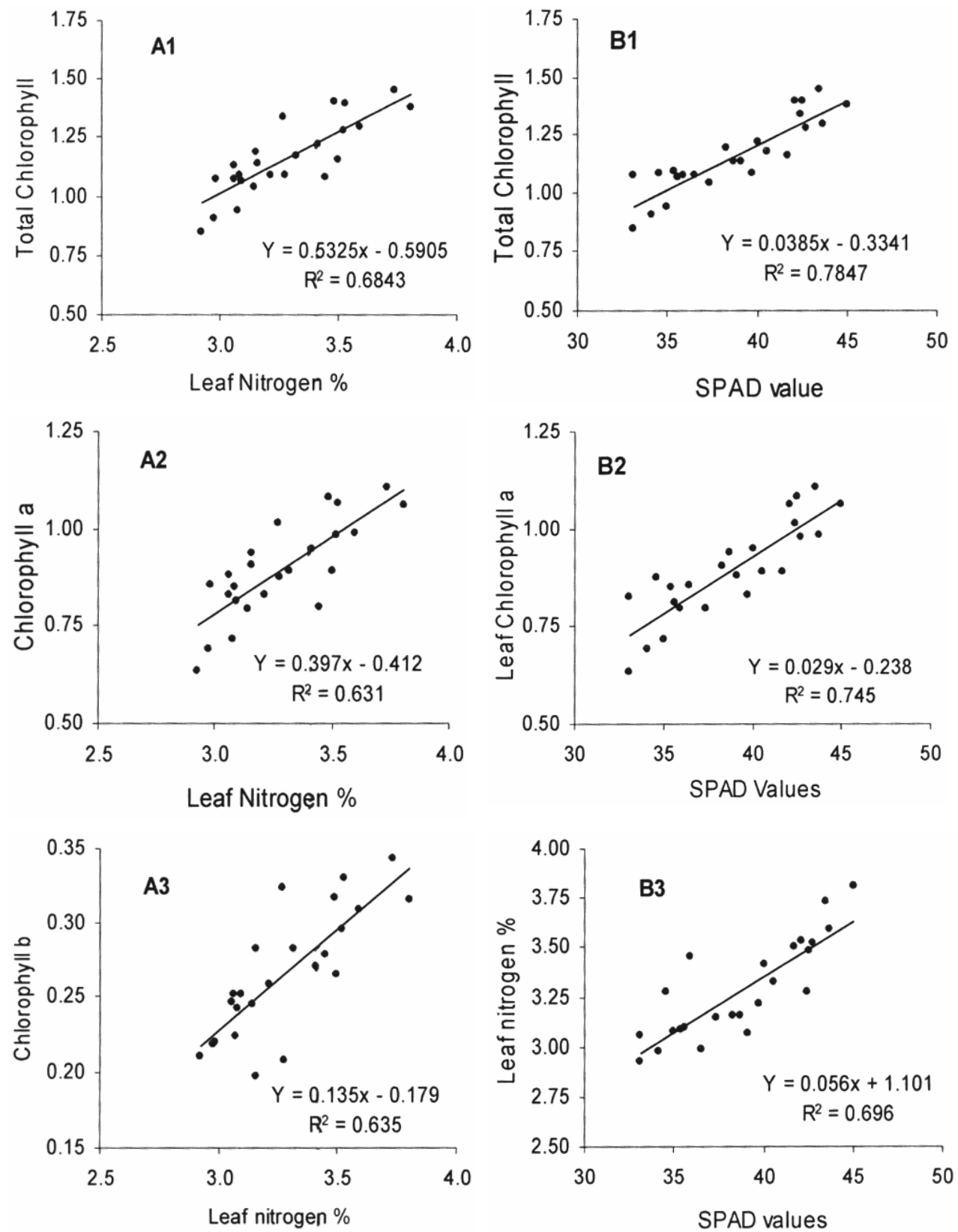

Fig. 1. Relationship between A. Leaf nitrogen \% and A1. Total leaf chlorophyll, A2. Chlorophyll-a, A3. Chlorophyll-b and B. SPAD values and B1. Total leaf chlorophyll, B2. Chlorophyll-a, B3. Leaf nitrogen \% at flowering stage of traditional rice varieties during T. Aman 2003. 


\section{Changes of SPAD (Soil plant analysis development) values over time}

SPAD reading indicates the plant nitrogen status and the amount of nitrogen to be applied are determined by the physiological nitrogen requirement of crop at different growth stages. The chlorophyll meter quantifies the greenness or relative chlorophyll content of leaves (Inada, 1985; Kariya et al., 1982). The critical or threshold SPAD value is important and that indicates the leaf area based critical nitrogen concentration in rice leaves. Peng et al. (1996) reported that SPAD threshold value of 35 is equal to 1.4 to $1.5 \mathrm{~g} \mathrm{~N}$ per $\mathrm{m}^{2}$ of leaf area in semi-dwarf Indica rice varieties.

Fig. 2 represents the changes of SPAD values of rice cultivars over time. Results revealed that all the varieties showed identical SPAD values around or over 35 at 15 DAT and increased slowly upto 27 to 33 DAT and thereafter decreased slightly and again showed increasing trend starting from 55 to 60 DAT, which again slowed down at around 72 to 78 DAT. Four distinct patterns of SPAD values by the cultivars were observed. Among these, Badiruzzman represents $\underline{1}^{\text {st }}$ trend that attained the peak at 30 DAT and continued with decreasing trend irrespective of nutrient levels upto the end. In this pattern, the mean value was 37.21 and attained the peak of 41.38 at 30 DAT for nitrogen (80 $\mathrm{kg} / \mathrm{ha}$ ) treatment and gone through distinctly gaining the higher value compared to zero nitrogen and cowdung treatments, while zero nitrogen treatment gone intermediately upto $72 \mathrm{DAT}$ and after that cowdung overlap the zero nitrogen and ended the same way.

The $\underline{2}^{\text {nd }}$ trend representing three varieties (Golapi, Laichi, and Malanchi) attained the peak at around 27 to 33 DAT and continued with decreasing trend irrespective of nutrient levels upto 57 to $60 \mathrm{DAT}$, and thereafter increased and slowed down at about 72 DAT and ended by the same fashion. However, Golapi attained the peak (43.75) at 27 DAT, Laichi peaked (44.59) at 30 DAT and Malanchi attained the peak (41.37) at 33 DAT of nitrogen $(80 \mathrm{~kg} / \mathrm{ha})$ treatment. These three varieties showed the mean SPAD values of 36.44, 36.13, 36.37, and ended at 21.79, 19.52, 20.90, respectively, with the mean of 20.73 irrespective of nutrient levels for whole growing period.

Basfulchikon and Barud represented the $\underline{3}^{\text {rd }}$ trend that started with a higher magnitude and attained the peak at around 30 DAT and continued with decreasing trend in a long way irrespective of nutrient levels and again upright creating a bend towards 75 DAT and slowed down until end. Here, both the varieties attained their peak values of 44.37 and 44.71, respectively, at 30 DAT and slowed down upto 60 to 63 DAT and again increased towards 75 DAT, and slowed down until the end. Basfulchikon and Barud performed a higher SPAD 


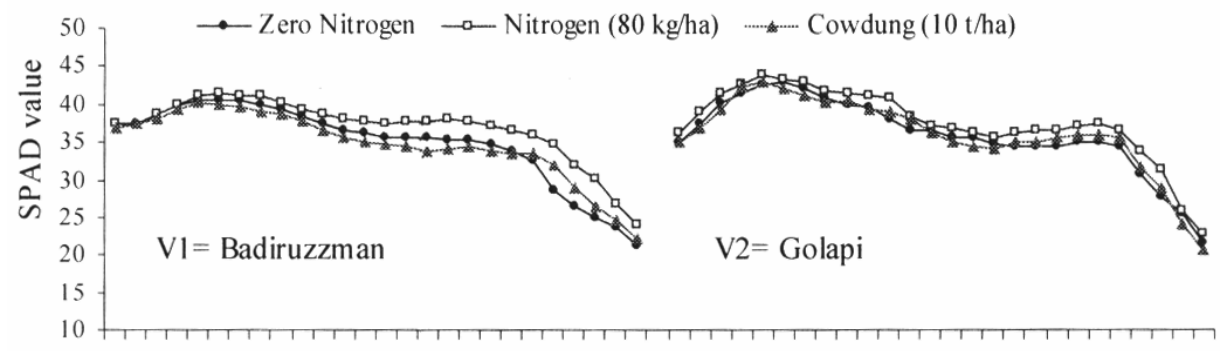

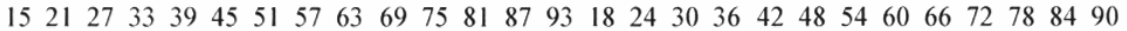
Days after transplanting (DAT)

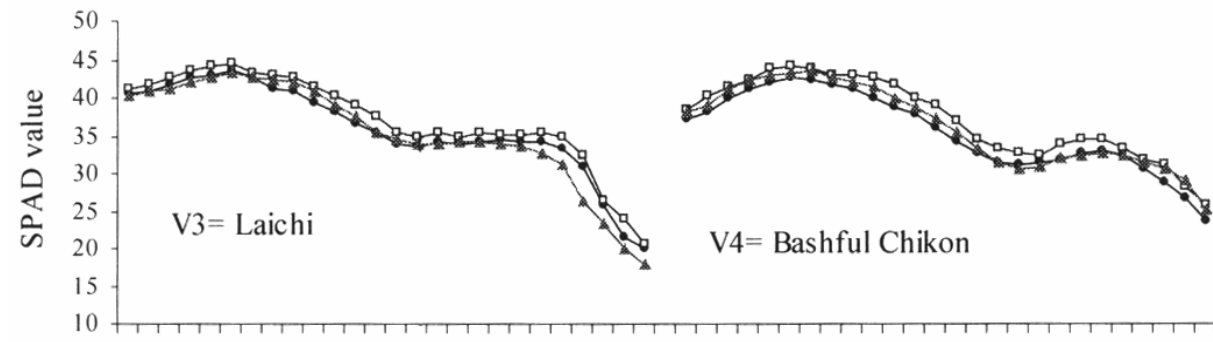

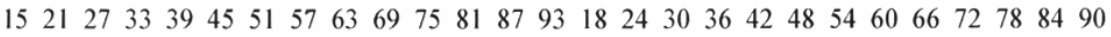
Days after transplanting (DAT)

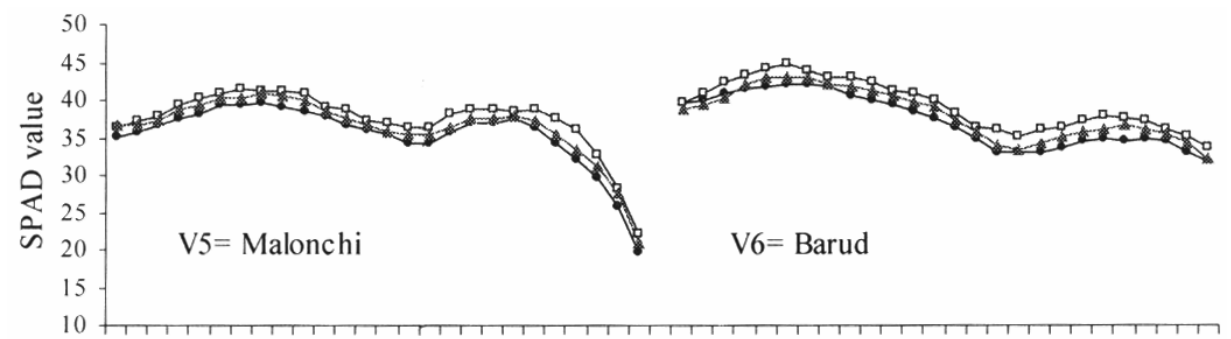

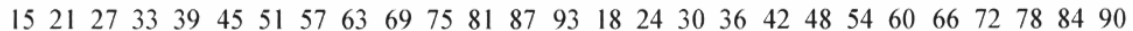
Days after transplanting (DAT)

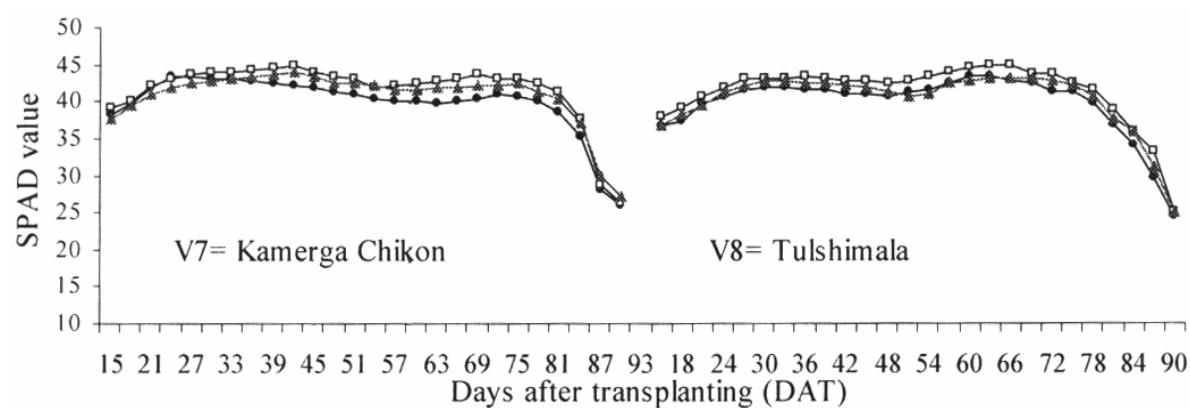

Fig. 2. Genotypic variations of traditional rice varieties for the change in SPAD values during T. Aman, 2003. 
value during most of the growth period and also ended higher value compared to other varieties. The mean SPAD values of Basfulchikon and Barud were 36.28 and 38.24, respectively, for the whole growth period.

Finally, the $\underline{4}^{\text {th }}$ trend represented the two smaller seeded varieties i.e., Kamerga chikon and Tulshimala (aromatic) that maintained a considerable higher magnitude of SPAD values upto 72 DAT without creating distinct peak and thereafter slowed down upto the end. In this case, Kamerga chikon and Tulshimala started with considerably higher SPAD value (38.39 and 37.08, respectively) at 15 DAT and attained peak at 42 and 63 DAT with the value of 44.84 and 45.02 , respectively. The mean SPAD values of these two were over 40 while they ended at around 25.

\section{References}

Ali, M. A. 2005. Productivity and resource use efficiency of rice as affected by crop establishment and nitrogen management. Ph. D Dissertation. UPLB, Philippines. 180 P.

Balasubramanian, V., C. H. M. Vijaykumar and M. I. Ahmed. 1999. Pre-flowering dry matter and yield component relationships in rice hybrids. Indian J. Plant Physiol. 4, 1(NS):55-57.

Borah, R. C. and S. C. Dek. 1994. Variation in uptake, assimilation and use efficiency of nitrogen of low land Aus rice. J. Agric. Soc. North-East India 7(1): 92-94.

Cassman, K. G., M. G. Kropff, J. Gaunt and S. Peng. 1993. Nitrogen ue efficiency of irrigated rice: what are the key constraints? Plant and Soil 155/156: 359-362.

De Datta. S.K., and R.J. Buresh. 1989. Integrated nitrogen management in irrigated rice. Adv. Agron. 10: 143-169.

Gourley, C. J. P., D. L. Allan and M. P. Russelle. 1993. Defining phosphorus efficiency in plant. In: Barrow, N.J. (Eds.). Plant nutrition from genetic engineering to field practice. Kluwer Academic Publishers, pp. 363-366.

Hussain, F., K. F. Bronson, Y. Singh, B, Sing and S. Peng. 2000. Use of chlorophyll meter efficiency indices for nitrogen management of irrigated rice in Asia. Agron. $J$. 92: 875- 779.

Inada, K. 1985. Spectral ratio of reflectance for estimating chlorophyll content of leaf. Jap. J. Crop Sci. 54: 26 1-265.

Islam, M. Sh., M. R. Islam and Z. U. Ahmed. 1998. Evaluation of nitrogen management based on chlorophyll meter (SPAD) value in modern rice varieties under wet and dry seasons. Bangladesh Agron. J. 8 (1\&2): 37-45.

Kariya, K. A. Matsuzaki and H. Machida.1982. Distribution of chlorophyll content in leaf blade in rice plant. Jap. J. Crop Sc. 51: 134-135.

Miah, M. A. M. and Z. U. Ahmed. 2002. Comparative efficiency of the chlorophyll meter technique, urea super granule and pnlled urea for hybrid rice in Bangladesh. In: "Hybrid rice in Bangladesh: Progress and future strategies". Pp. 43-50. 
Miah. M. N. H., T. Yoshida and Y. Yomamoto. 1997. Effect of nitrogen application during ripening period on photosynthesis and dry matter production and its impact on yield and yield components of semi dwarf indica rice varieties under water culture conditions. Soil Sci. and Plant Nut. 43(1): 205-217.

Panaullah G. M., Z. U. Ahmed, P. K. Saha, B. Rahman, and M. S. Islam, V. Balasubramanian and K. F. Broson. 1999. The chlorophyll meter technique and traditional split-application method of nitrogen fertilizer of rice in Bangladesh: A comparative study. Paper presented on the "workshop cum group meeting on CREMNET program in India”, Tanjuvar, Tamil Nadu, 24-27, August, 1999.

Peng, S., P. V. Garcia, R. C. Laza, A. L. Sanico, R. M. Visperas and K. G. Cassman. 1996. Increasd N-use efficiency using a chlorophyll metter on high-yielding irrigated rice. Field crop Res. 47: 243-252.

Pinto, M. G., R. M. Boddey, B. J. R. Alves and S. Urquiaga. 2001. Productive potential of genotypes of wetland rice grown in low fertility soil without addition of fertilizer N. Agronomia. 35(1 -2): 43-46.

Singh.U, J. K. Ladha, E.G. Castillo, G. Punzalan, A. Tirol-Padre and M. Duqueza. 1998. Genotypic variation in nitrogen use efficiency in medium and long duration rice. Field Crops Res. 58: 3 5-53.

Takabe, M., T. Yoneyama, K. Inada and T. Murakam. 1990. Spectral reflectance ratio of rice canopy for estimating crop nitrogen status. Plant Soil. 122: 295-297.

Yoshida, S. 1983. Rice. In: Smith, W. H.. Banta, S.J. (Eds.) Potential productivity of fiend crops under different environments. International Rice Research Institute, Los Banos, Philippines. 